\title{
Investigation of the Influence of Powder Moisture on the Spreadability Using the Spreading Tester
}

\author{
Marco Mitterlehner ${ }^{1}$, Herbert Danninger ${ }^{1}$, Christian Gierl-Mayer $^{1}$, and Harald Gschiel ${ }^{2}$ \\ ${ }^{1}$ Institut für Chemische Technologien und Analytik, TU Wien, Wien, Austria \\ ${ }^{2}$ voestalpine Böhler Edelstahl GmbH \& Co KG, Kapfenberg, Austria
}

Received November 13, 2020; accepted November 20, 2020; published online January 14, 2021

\begin{abstract}
Moisture is often regarded as one of the main reasons for poor processability of powders using Laserpowder bed fusion (L-PBF) processes. To determine the influence of moisture on the spreadability, a superalloy powder IN718 commonly used for L-PBF processes has been conditioned in two different states: once in the asreceived and dry condition and once in a moist condition obtained by storing the powder for four weeks in an atmosphere containing a relative humidity of $75 \%$. Using a selfbuilt spreading tester and a subsequent analysis method specially developed for testing the spreadability of a powder, the differently conditioned IN718 powder batches have been investigated regarding the surface roughness and flatness of the powder layers. Additionally, the formation of empty spots between the powder particles in the top layer has been studied.
\end{abstract}

Keywords: Additive Manufacturing, Powder bed fusion, IN718, Moisture, Spreadability, Testing, Python

Untersuchung des Einflusses der Feuchte von Pulvern auf die Rakelfähigkeit mit dem Spreading Tester

Zusammenfassung: Feuchte wird oft als einer der Hauptgründe für schlechte Verarbeitbarkeit von Pulvern mittels L-PBF Prozessen angeführt. Um den Einfluss der Feuchte auf die Rakelfähigkeit zu untersuchen, wurde ein inertgasverdüstes Superlegierungspulver IN718, welches üblicherweise für L-PBF Prozesse verwendet wird, unterschiedlich konditioniert: einmal trocken und somit wie im Anlieferungszustand und einmal feucht, durch eine vierwöchige Lagerung des Pulvers in einer Atmosphäre mit einer relativen Luftfeuchtigkeit von $75 \%$. Mit Hilfe eines selbstgebau-

\footnotetext{
M. Mitterlehner ( $\bowtie)$

Institut für Chemische Technologien und Analytik, TU Wien,

Getreidemarkt 9/164-CT,

1060 Wien, Austria

marco.mitterlehner@tuwien.ac.at
}

ten Prüfstandes und einer eigens für die Prüfung der Rakelfähigkeit eines Pulvers entwickelten Analysemethode wurden die unterschiedlich konditionierten IN718 Pulverchargen hinsichtlich der Rauigkeit und Ebenheit der aufgetragenen Pulverschichten untersucht. Zusätzlich wurde auch die Bildung leerer Flächen zwischen den Pulverpartikeln in einer einzigen aufgetragenen Schicht untersucht.

Schlüsselwörter: Additive Fertigung, Pulverbetttechnologie, IN718, Feuchte, Rakelfähigkeit, Prüfen, Python

\section{Introduction}

Nickel-based superalloys combine high-temperature strength, toughness, corrosion resistance, and good fatigue life, which is why they are widely used in the aerospace and energy industries [1-3]. Since this also makes them difficult to process, especially through machining, near-net-shape processing techniques such as additive manufacturing of these materials has gained more and more popularity over the last decades [1,3].

An initial powder characterization to determine whether or not a powder is suitable for a build job has always been of particular interest, due to the high cost and long duration of such a build job. Many well-known powder characteristics, such as flowability or apparent density, are therefore tested in the field of additive manufacturing techniques that use powder bed systems. Of particular interest is the flowability of a powder, whereby a distinction must be made between flow time and flowability. The former is measured by means of a calibrated Hall funnel, and the latter refers to the totality of various measurable variables that are combined to describe the complex behaviour of powders when mobilised, such as flow time, but also, for example, cohesiveness, particle size and shape, and others $[4,5]$. Apart from these well-known powder properties, new testing methods are available as well [6-9]. In any case, the quality of the applied top powder layers, especially the filling as well as 
Fig. 1: Mass-related particle size distribution of the used L718 AMPO powder

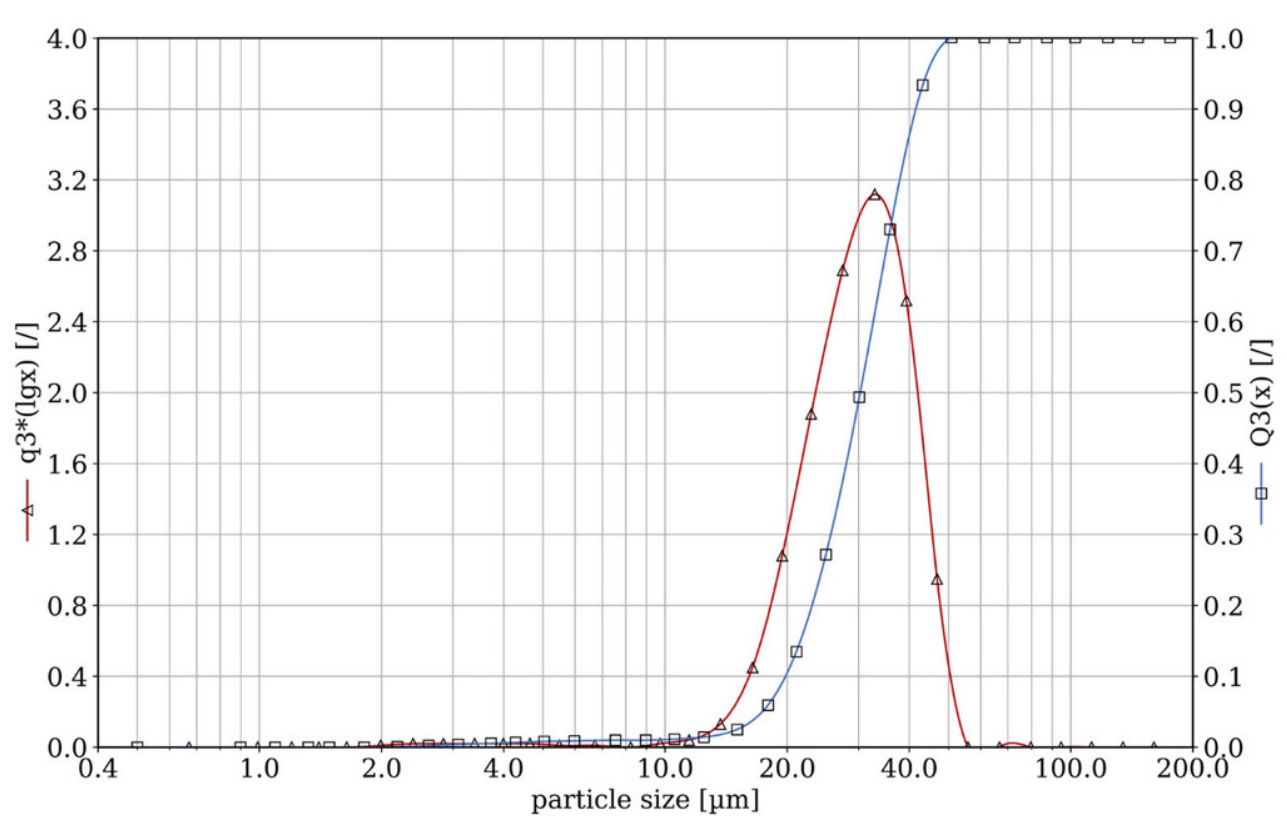

the homogeneity, is of crucial importance during the building process. Particularly assessing this quantitatively is of high practical importance, although it is a challenging job.

In Laser-powder bed fusion technologies, humidity is often claimed to be a huge problem. Especially when it comes to spreading the powder, humidity is suspected to result in a poor final quality of the printed components. Moisture in the printing chamber is associated with the formation of pores in the built components, as investigated in [10]. In this study, it was also found that some materials such as aluminium alloys are more affected than others, as e.g. an investigated nickel-based superalloy (IN718). Regarding powder characteristics such as the flowability, which can be influenced by particle size and shape, adsorbed water on the powder surface is also often claimed to be detrimental [11-13]. Since adsorbed water always plays a major role here, several attempts have been made to quantify the water adsorption in the recent past. Thereby, Karl Fischer titration appears to be the most reliable one [14, 15].

To investigate the impact of adsorbed water on the spreading behavior-or also called spreadability - of a gas atomized IN718 powder, a self-built testing device-the socalled Spreading Tester-was used. The powder used was then once tested in a dry state and once in a humid state. With a specially developed subsequent analysis method for evaluation of the spread surfaces, differences therein were investigated.

\section{Experimental Procedure}

\subsection{Powder Used}

An inert gas atomized IN718 powder grade of voestalpine Böhler Edelstahl GmbH \& Co KG, available under the designation L718 AMPO, was used for this study. Fig. 1 shows the mass-related particle size distribution measured by laser diffraction using a Sympatec HELOS/BF system. The distribution is minimally skewed left but overall, very uniform and narrow. The particle size ranges from 15 to $55 \mu \mathrm{m}$ and the mass-median-diameter $\left(d_{3}, 50\right)$ of the powder is $30.4 \pm 0.1 \mu \mathrm{m}$.

In Fig. 2 an SEM image of the L718 AMPO powder used, taken with a JEOL JCM-6000, can be seen. The shape of the particles is mostly well spherical, but, nevertheless, there are also a few non-spherical particles as well as fused agglomerates consisting of smaller particles $(<10 \mu \mathrm{m})$. Furthermore, some of the particles are partially covered with satellites, and yet, the overall shape is considered to be more or less spherical and uniform.

The flow time according to ISO 4490:2018 was also measured. The powder was found not to flow freely through the calibrated Hall funnel. Nevertheless, it could be spread using the Spreading Tester without any problems.

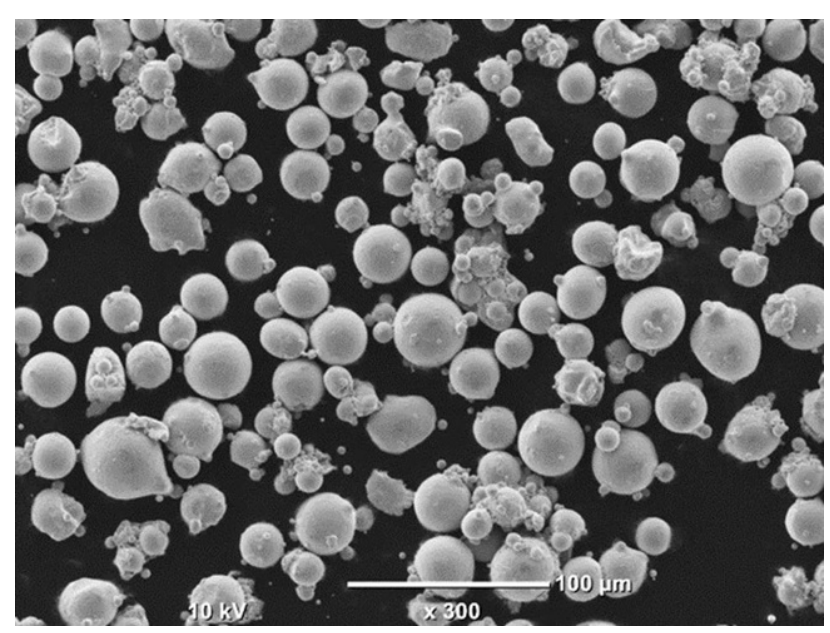

Fig. 2: SEM image of the used L718 AMPO powder 


\subsection{Powder Conditioning}

To investigate the influence of adsorbed water on the spreadability of the used powder and therefore on the quality of a spread powder layer, the powder was conditioned once in a dry and once in a humid state. For the dry state, the powder was stored in a desiccator above silica gel for four weeks, which is intended to remove all moisture from the environment, making the powder "dry". For the humid state, the powder was also stored in a desiccator for four weeks, but above a saturated sodium chloride solution, through which a relative humidity of $75 \%$ could be achieved [15], making the powder "humid".

\subsection{Spreading}

To test the spreadability of powders, a special tester was developed-the so-called Spreading Tester shown in Fig. 3. It is controlled by a LabVIEW program, and thus parameters, such as the number of spread layers, layer thickness, spreading velocity, the mimicked machine, and much more, can be varied. In addition to these software parameters, other parameters, such as the distance between the recoater blade and the building platform-also known as the gap size-the angle of the recoater blade, or even the recoater blade itself, can be changed. Yet, in this study an EOS M280 machine was mimicked using an HSS recoater blade with a rhombic shape as shown in Fig. 4.

In Fig. 5 the simplified spreading strategy of an EOS M280 machine can be seen. First (1), the building platform moves down and thereby adjusts precisely the layer thickness. Next (2), the recoater blade moves forward, spreading the powder on the building platform. Now, the powder would be selectively molten, but since the Spreading Tester is only used to spread layers of powder, this step is not necessary. At the end (3) the building platform moves
Fig. 4: HSS recoater blade

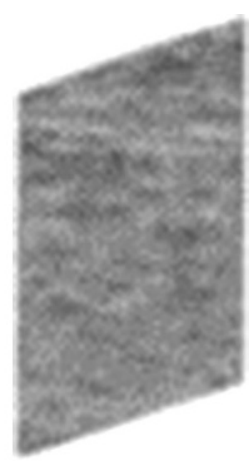

downwards to protect the layer when the recoater blade moves back to its initial position.

In this study, two different evaluation methods were used. The first one investigates the formation of empty spots in a single spread layer, whereas the second one investigates the surface roughness and flatness of several spread layers. Both methods are now explained in more detail.

\subsection{Investigation on the Formation of Empty Spots}

In other words, examining the formation of empty spots means examining the surface coverage of a single spread powder layer. It is of course essential to spread a dense powder layer in order to selectively melt enough material in the actual layer and thus prevent defects during printing. To do so, two aspects are decisive, namely the gap size $(\delta)$ and the layer thickness $\left(d_{l}\right)$. Thus, the layer thickness in the first layer is determined by $\delta$, and it depends on the layer thickness if, in each further layer, it is equal to the gap size because of two facts: the first one is that there are voids between the particles in the layer even in case of maximum

Fig. 3: Spreading Tester

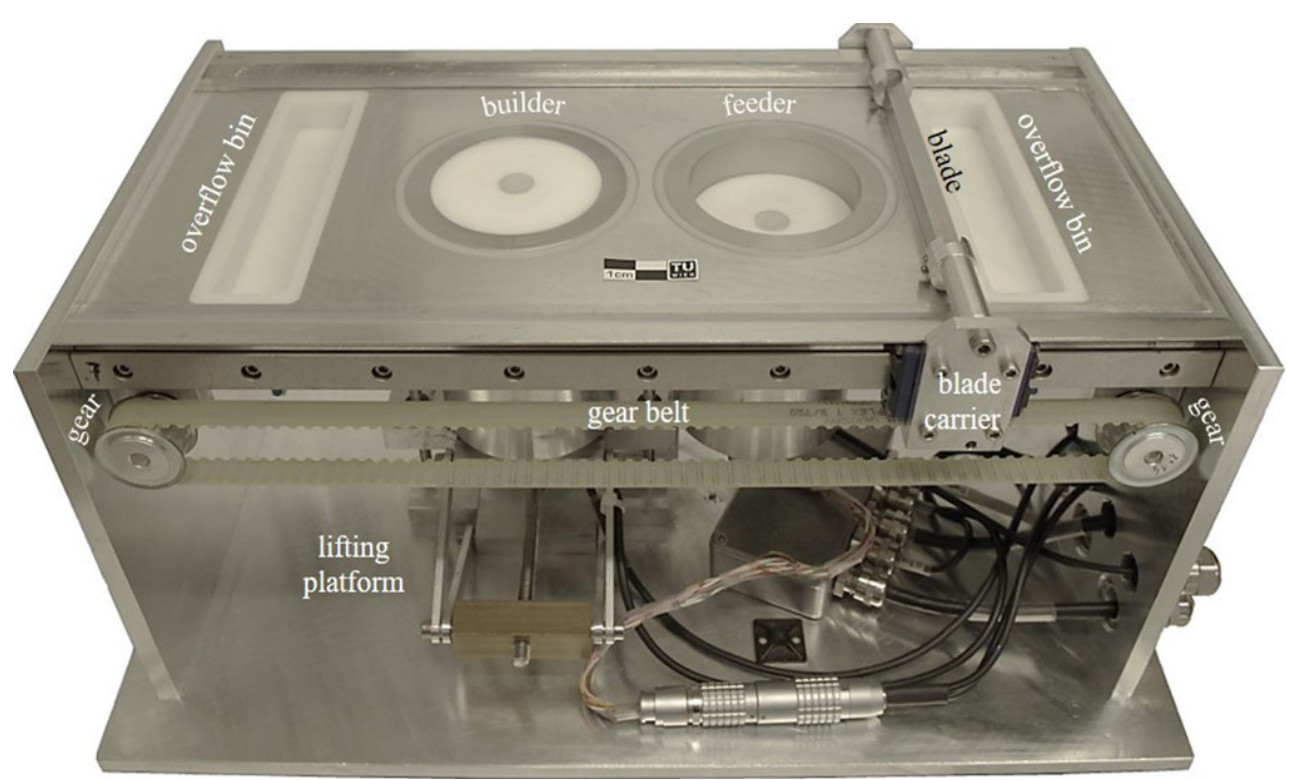


Fig. 5: Simplified spreading strategy of an EOS M280 ( $B$ builder; Ffeeder)

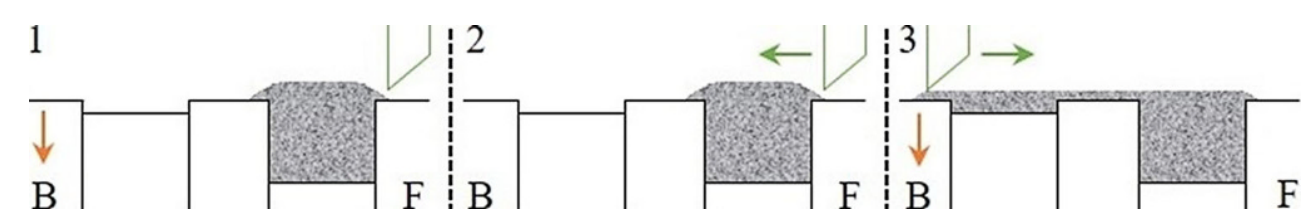

$\mathrm{h}_{\mathrm{V}, \mathrm{n}}$

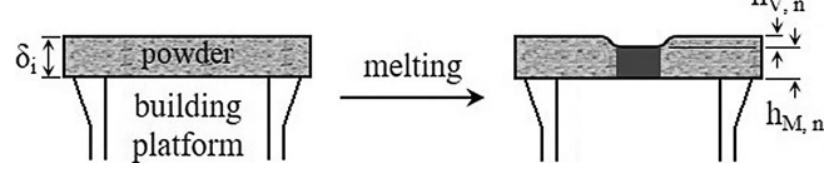

Fig. 6: Compaction of melted powder

Fig. 7: Uniform process

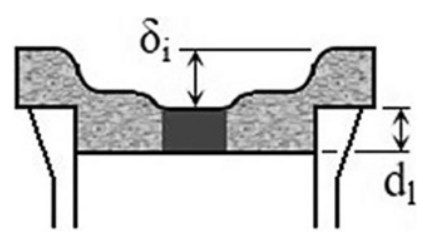

packing density (74\% for spheres of constant particle size) and therefore, after selectively melting the powder, the remaining now solidified area is lowered compared to the surrounding powder as shown in Fig. 6. There the initial gap size $\left(\delta_{i}\right)$, the height of the selectively molten material in the $n$th layer $\left(h_{M}, n\right)$ and the height difference by which the surface of the molten material is lowered due to the voids also for the $\mathrm{n}$ th layer $\left(\mathrm{hv}_{\mathrm{v}} \mathrm{n}\right)$ are marked. Then to grant a uniform process in every further layer, the layer thickness has to be adapted to the gap size as shown in Fig. 7. Of course, this can also be done the other way round so that the gap size is defined through the layer thickness. Thus, only if the layer thickness is equal to the height of the molten material in the first layer $\left(d_{l}=h_{M}, 0\right)$, the upper end of molten material would be at the same level as the initial position of the building platform in the next layer. Therefore, the relationship given in Eq. 1 must be fulfilled, in which $v_{f}$ is the amount of the void fraction between the powder particles.

Equation 1: Correlation Between Layer Thickness $\left(d_{l}\right)$ and Initial Gap Size $\left(\delta_{\mathrm{i}}\right)$ for a Uniform Process

$\delta_{i}=\frac{d_{l}}{1-v_{f}}$

Now, if the gap size was smaller than all of the particles, no powder particles could pass (Fig. 8a). The resulting layer would then probably have a high amount of empty space (approaching 100\%) when spread on solid ground like the building platform or, later, the molten material from the layer below.

If the gap size during spreading on these grounds is within the range of the size of the particles in the powder used, at least the smaller particles can pass. Yet, this will result, on the one hand, in a segregation of the powder (Fig. 8b), whereby smaller particles remain in the spread layer and bigger ones remain in the powder heap. On the other hand, a bigger particle can get stuck in front of the recoater blade and thus block it for smaller particles to pass (Fig. 8c), which would result in the formation of empty spots as simulated in [16].

All these aspects do not apply, however, as soon as the powder is spread in a loose powder bed, as the powder can be compacted or easily moved in this bed as it is not fixed locally (this does not apply to electron beam melting, as there the powder is slightly sintered before each layer). As shown in [17], not only the gap size influences the formation of these empty spots but also the spreading velocity. Thereby, it was observed that the faster a powder is spread, the less dense the resulting layer.

Since the powder is not melted during the examination with the Spreading Tester, the correlation from Eq. 1 does not have to be taken into account, but the following applies to grant a uniform process: the gap size is equal to the layer thickness. In order to investigate the formation of empty spots, just one single layer of powder is spread for which the gap size has previously been adjusted precisely. After that the builder-on which the layer has been spread-is removed from the tester and placed under a digital microscope (Keyence VHX-5000). There, three-dimensional images are taken at nine spots (shown in Fig. 9) in the spread powder layer using $800 \times$ magnification. These images each consist of 30 single images that are stitched together and therefore have a size of about $1.1 \times 1.1 \mathrm{~mm}$. This image acquisition process is always done carefully in order not to change the morphology of the spread layer.

In Fig. 10 an example of these three-dimensional images is shown. Taking a closer look at the magnified area in the upper left corner, it can be seen that the software of the used digital microscope somehow smoothens the surface, since the area right next to the particles is not dark blue-as

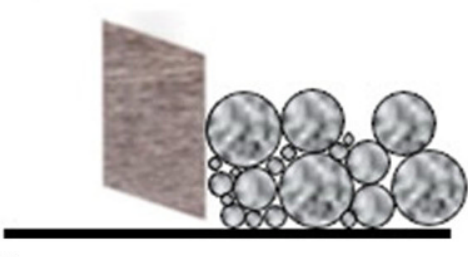

a

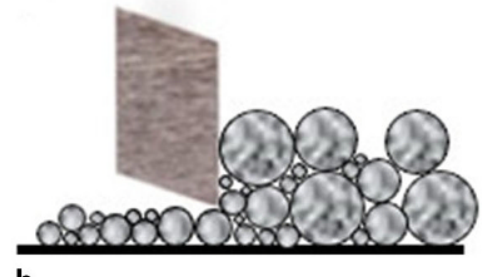

b

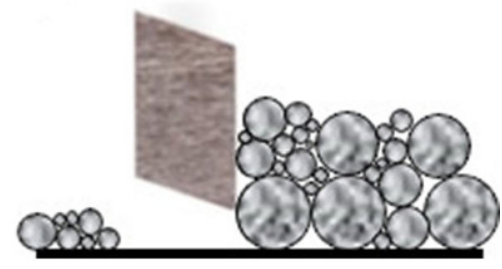

c

Fig. 8: Spreading scenarios (a too small gap size, b segregation, $\mathbf{c}$ jamming) 
Fig. 9: Measuring spots
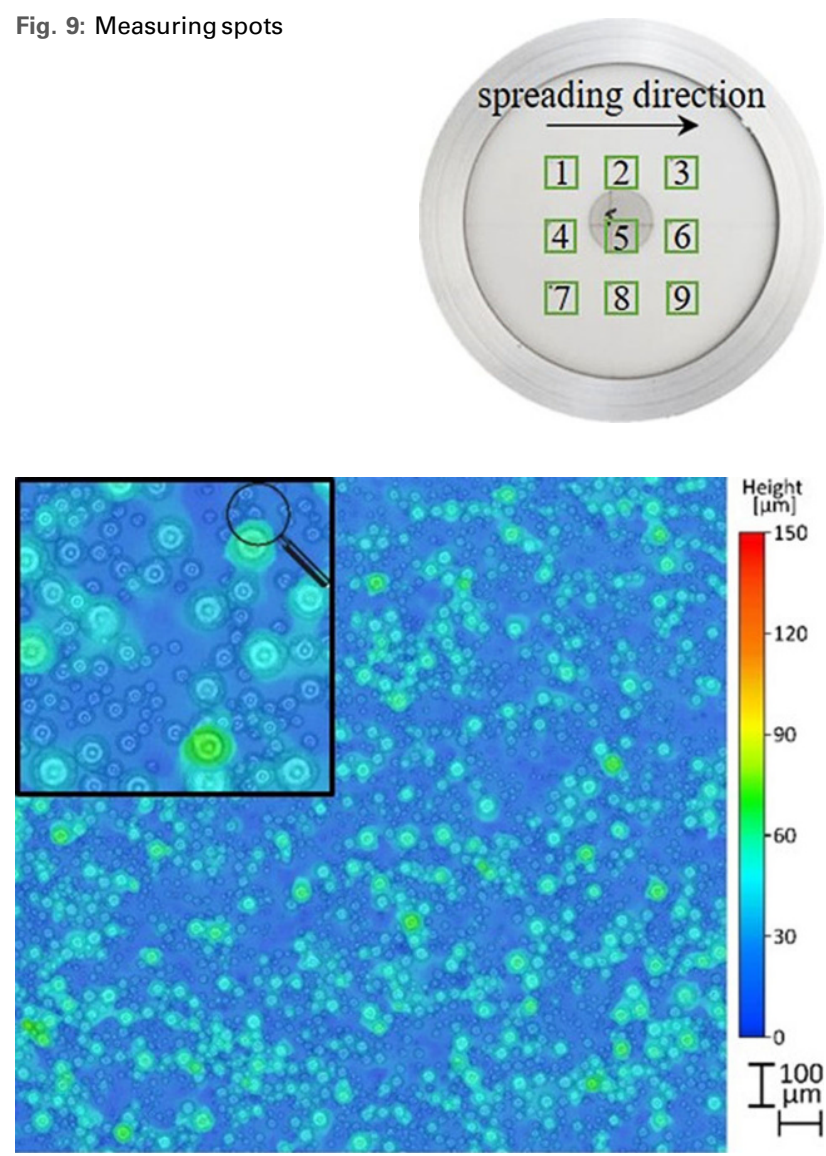

Fig. 10: Three-dimensional image of a single spread layer

it should be if the height at this position were zero. Therefore, the building platform's height is not always zero, but somehow distributed within a few microns (which is in fact an-inevitable-artefact generated by the software). Now to evaluate the amount of empty space between the particles, the height data of each pixel in the image are used. These data can be exported by the microscope software and then be plotted as shown in Fig. 11. Obviously, the height distribution consists of two single peaks where the lower peak can be assigned to the empty spots and the higher one

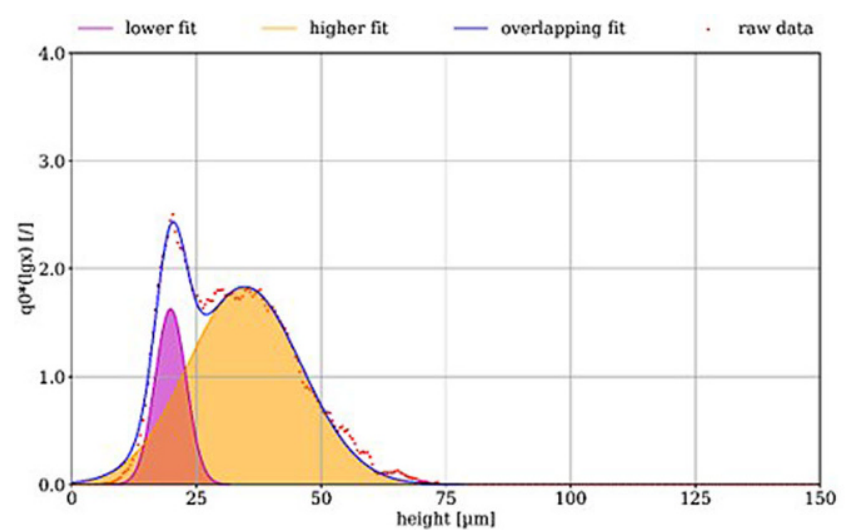

Fig. 11: Plotted height distribution corresponding to the spread surface in Fig. 10

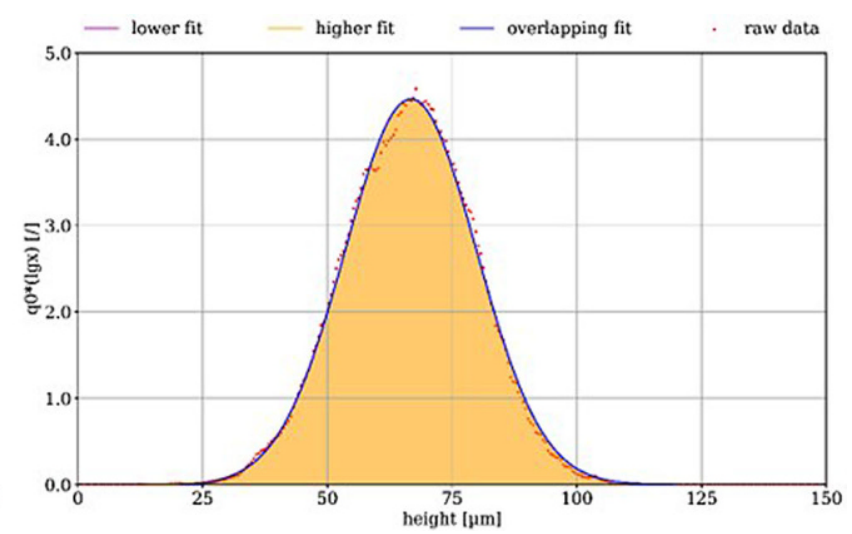

to the particles. The amount of empty space $(\psi)$ can now be quantified by first fitting peaks with a Gaussian shape into the height distribution and then by calculating the percentage of the area below the lower peak relative to the total area below all fitted peaks, as shown in Eq. 2.

\section{Equation 2: Amount of Empty Space}

$\psi=\frac{A_{\text {lower fit }}}{A_{\text {total }}} \cdot 100$

For the spreading test, a gap size of $40 \mu \mathrm{m}$ and a spreading velocity of $150 \mathrm{~mm} / \mathrm{s}$ were used. Since the Spreading Tester is only placed in a digestor in a lab, the atmosphere around it cannot be adjusted manually and thus the adsorbed water probably desorbs during spreading. In order to minimize this error, the powder was removed from the conditioning environment at the very last second and filled very quickly into the feeder. Then the test was started. Thus, for testing the formation of empty spots, in which only one single layer is spread, the conditioned state of the powder can be assumed to remain practically unchanged until after the test had been performed.

\subsection{Investigation on the Surface Roughness and Flatness}

For describing and assessing the quality of the top spread layer using a powder bed system, a new method has been developed, which is discussed in brief: In contrast to the investigation on the formation of empty spots, several layers are spread. After that the top spread layer is examined using the digital microscope as well, whereby threedimensional images (Fig. 13) in the same way as previously described and the same nine spots as shown in Fig. 9 are taken. A Python program written by the author then scans the three-dimensional images in two directions (horizontal and vertical) and thereby examines one line profile after the other searching for maxima occurring at the same location in both directions. By doing so, each of these maxima that are present in both scans is equivalent to one particle in the surface, as this is a unique feature in this kind of surface, also seen in Fig. 12. Therein also a perfect surface for this scenario can be seen, which consists of only spherical parti- 


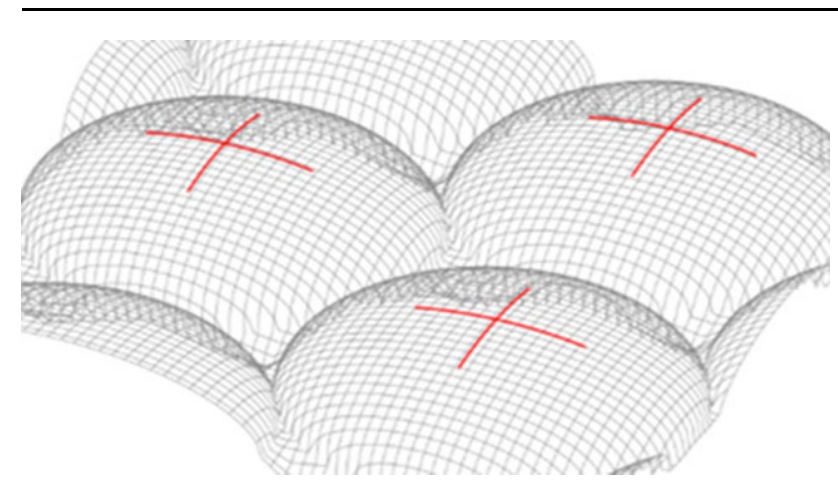

Fig. 12: Unique maximum in both directions

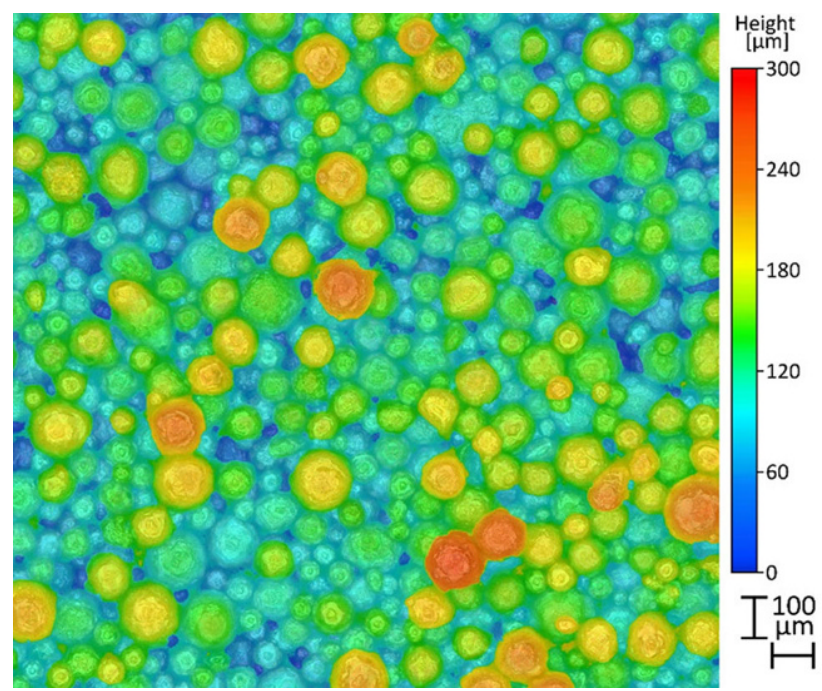

Fig. 13: Three-dimensional image of the top spread surface after several layers

cles with the same size of the mass-median-diameter $\left(d_{3,50}\right)$ and is packed closest (hexagonal or cubic, both achieving the same packing density [18]). This method is described in more detail in [19-21]. The surface evaluated with the method shown in Fig. 13 is shown in Fig. 14, where each particle found is marked with a black plus.

Using the particles detected in the surface as well as the height data of the recorded surface, several parameters can be calculated that allow us to assess the quality of a spread powder layer. For this, four different parameters have been determined in this study, whereby the size of the examined area of course plays a decisive role, which is why it was always kept the same. Thereby, the height $\left(\Delta \mathrm{H}_{\mathrm{Par}}\right)$ as well as the distribution of the height $\left(\Delta \mathrm{Q}_{\mathrm{Par}}\right)$ of the found particles, the surface area $(A)$, and the enclosed volume of the surface $\left(V_{\text {equ }}\right)$ are used as follows:

$\Delta \boldsymbol{H}_{\text {Par }}$ is defined as the difference in height within the surface between the lowest and highest particles visible from above and is called deviation of height. The parameter is used to describe the flatness of a surface and states that all the larger the deviation, the less flat the surface. Here, however, it should be considered that only images of the same size of the measured area should be compared, since

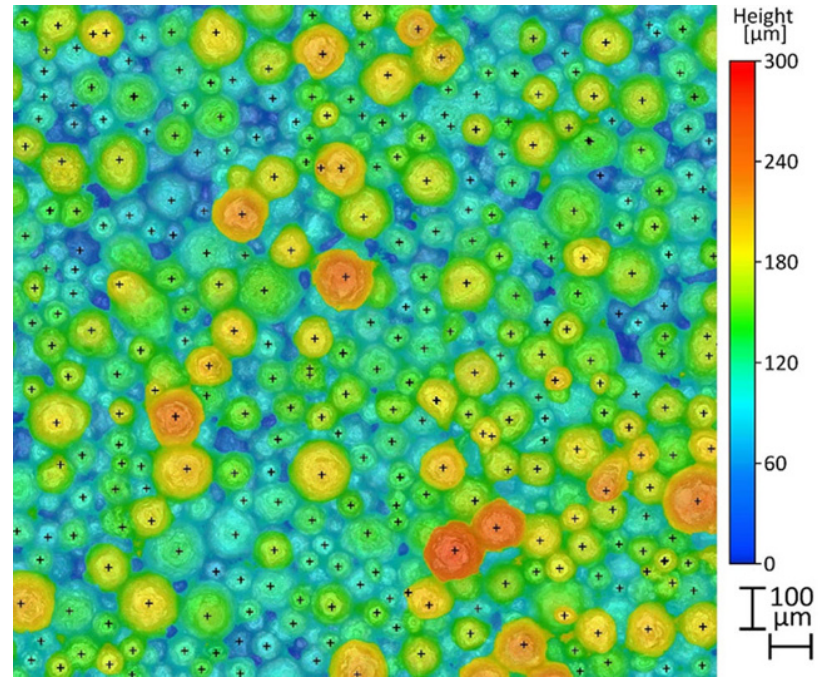

Fig. 14: Evaluated three-dimensional image of the top spread surface from Fig. 13

the probability of a very large deviation of height increases with the investigated area.

$\Delta \mathbf{Q}_{\text {Par }}$ is classified as the difference between the third quartile and the first quartile relating to the height distribution of the found particles and is called difference in quartiles. This is also referred to as the interquartile range, which is often used in statistics to describe the width of the distribution. The parameter states that the higher it is, the higher the interquartile range and therefore the wider the distribution. Put simply, the higher $\Delta \mathrm{Q}_{\mathrm{Par}}$, the wider the range in which the middle $50 \%$ of the particles appear and the rougher the surface. This parameter is virtually independent of the investigated area.

A is the surface area itself, which is calculated by triangulation of the surface. It states that the higher the surface area, the rougher the surface.

$\mathbf{V}_{\text {equ }}$ is the so-called equalizing volume. It is determined by placing a virtual perfectly flat plane in the surface. The enclosed volume between the plane and the surface, above and below the plane, that is equal is specified as $\mathrm{V}_{\text {equ. }}$. Thus, the volume enclosed above the plane corresponds to the volume of the powder and the volume enclosed below the plane corresponds to the volume of the cavities. The parameter states that the larger the volume, the rougher the surface.

For the spreading tests, a layer thickness as well as a gap size of $40 \mu \mathrm{m}$ were chosen and the spreading velocity was set to $150 \mathrm{~mm} / \mathrm{s}$. As mentioned before the atmosphere around the Spreading Tester cannot be adjusted manually. Thus, again the powder was removed at the very last second from the conditioning environment, filled very quickly into the feeder and the test was started. Yet, since for this investigation a total of 40 layers were spread, it could not be guaranteed that the conditioned state of the powder remained practically unchanged until after the test had been performed, as this takes some time. As a result, this test was even more similar to the real L-PBF process in which a dry inert gas atmosphere is used during printing, result- 
ing in a significantly lower humidity in the atmosphere than during the spreading test, which was also investigated in [22].

\section{Results and Discussion}

\subsection{Investigation of the Formation of Empty Spots}

In Fig. 15 the evaluated amount of empty space $(\psi)$ of the dry $(0 \%$ relative humidity, white bars) and humid ( $75 \%$ relative humidity, black bars) conditioned powder is shown. On the left side of the figure, the evaluated data for each spot and, on the right, the averaged value from all spots is depicted. The evaluated data of each spot shows that the amount of empty space for the humid conditioned powder is always higher in comparison to the dry one. This means that, in case of the humid conditioned powder, the spread layers are significantly less covered with powder. There is also a correlation between the position of the spot and the amount of empty space, which is caused by the tilt of the building platform, which is inevitable as it is not perfectly parallel to the recoater blade and cannot be adjusted with the required precision. Yet, since the building platform was never moved during these experiments, the tilt was always the same and the measured values can be compared to each other without any hesitations. In the area of spot number 5 , there is a cover in the centre of the building platform to protect the spindle underneath, as can be seen in Fig. 9. This cover is not perfectly tight and is therefore slightly raised, resulting in a significantly decreased gap size, which is why the evaluated values there are significantly increased.

To sum this up, moisture adsorbed on the powder surface has a clearly negative impact on the coverage of a single spread powder layer as long as the moisture is retained during spreading. Higher relative humidity levels thereby lead to less covered spread surfaces, which would be detrimental for the powder bed fusion process. Thus, if the relative humidity was at the same level during the entire build job inside the machine, it would not be successful.

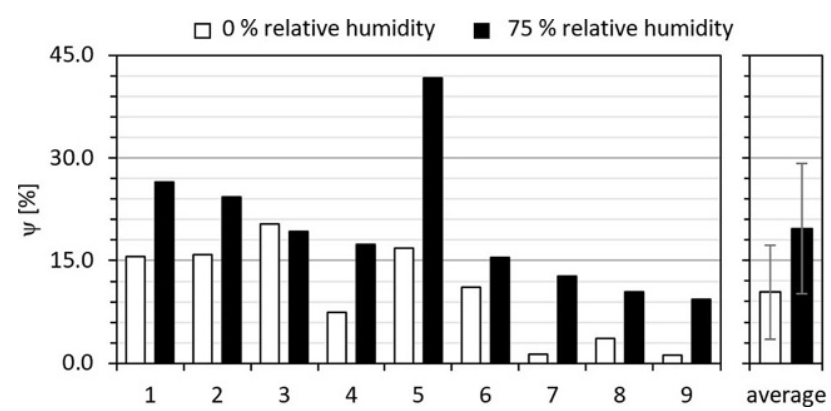

Fig. 15: Evaluated amount of empty space $(\psi)$ after four weeks of stor age at $0 \%$ (white bars) and $75 \%$ relative humidity (black bars)

\subsection{Investigation on the Surface Roughness and Flatness}

Since more than one layer was spread here, it should be mentioned that, even despite the non-measurable flow time, the powder could be spread without any problems.

In Fig. 16 the evaluated deviation of height $\left(\Delta \mathrm{H}_{\mathrm{Par}}\right)$ can be seen. In contrast to the investigation on the formation of empty spots described previously, there is no clear trend that the deviation of height is always higher for one of the differently conditioned powders. Thus, the average value is considered, which indicates that the spread surface using the humid conditioned powder is slightly flatter. Nevertheless, the values are in the range of scatter of the other.

The evaluated interquartile range $\left(\Delta \mathrm{Q}_{\mathrm{Par}}\right)$ is shown in Fig. 17. As with the deviation of height, no clear trend can be observed regarding improved values of any of the conditioned states. Thus, looking at the averaged values on the right, this indicates that the spread surface using the humid conditioned powder is marginally smoother. But again, the values are still in the range of scatter.

Fig. 18 shows the evaluated surface area (A). Again, there is no clear trend regarding improved values of any of the conditioned states. Therefore, looking at the averaged values on the right, it is also indicated that the spread surface using the humid conditioned powder is slightly smoother, whereby again the values are more or less within the scatter of the other.

In Fig. 19 the evaluated equalizing volume $\left(\mathrm{V}_{\text {equ }}\right)$ is shown. Here, the same trends referred to the single positions seen for the surface area before can be observed. This further means that there is no clear trend regarding

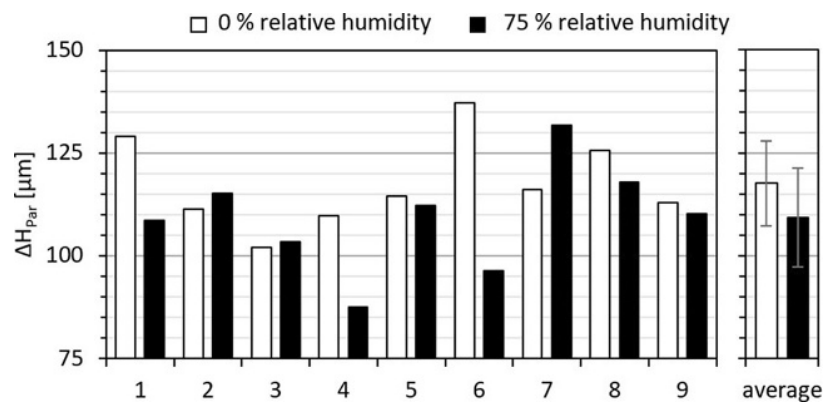

Fig. 16: Evaluated deviation of height $(\Delta \mathrm{HPar})$ after four weeks of storage at $0 \%$ (white bars) and $75 \%$ relative humidity (black bars)

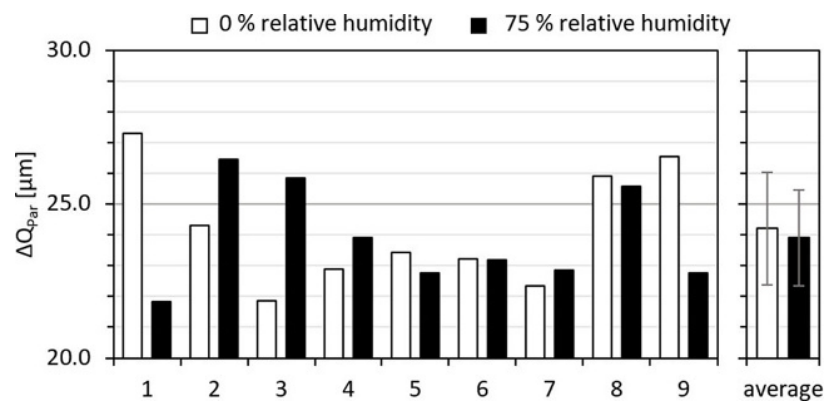

Fig. 17: Evaluated interquartile range ( $\triangle \mathrm{QPar}$ ) after four weeks of storage at $0 \%$ (white bars) and $75 \%$ relative humidity (black bars) 


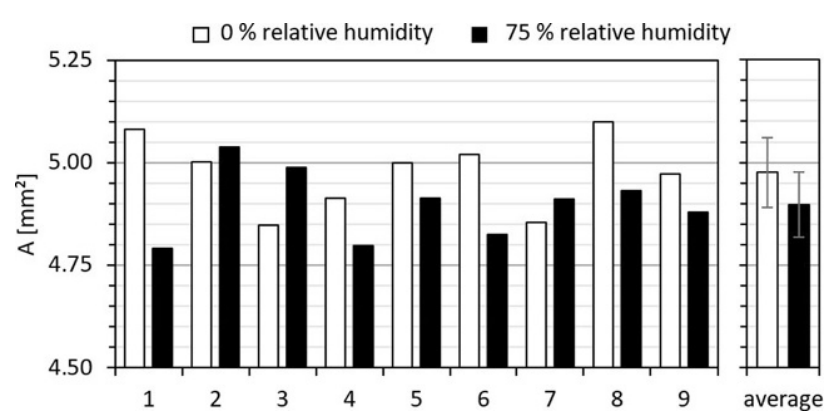

Fig. 18: Evaluated surface area $(\mathrm{A})$ after four weeks of storage at $0 \%$ (white bars) and $75 \%$ relative humidity (black bars)

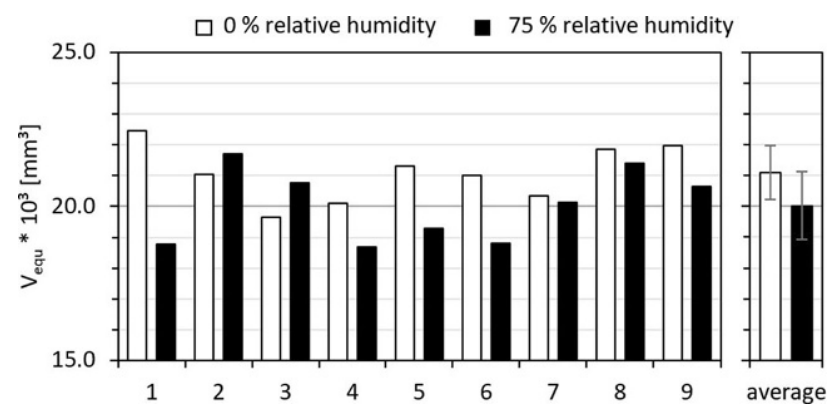

Fig. 19: Evaluated equalizing volume $\left(V_{\text {equ }}\right)$ after four weeks of storage at $0 \%$ (white bars) and $75 \%$ relative humidity (black bars)

improved values of any of the conditioned states. Looking at the averaged values on the right, it is again indicated that the spread surface using the humid conditioned powder is slightly smoother, whereby the values are more or less within the scatter of the other.

To conclude this test, all parameters indicate the same trend that, if a larger number of layers has been spread, the top spread surface for the humid conditioned powder will be slightly flatter and smoother, whereby the parameters describing the surface are always very similar and within the scatter range of each other. Therefore, it can be said that the relative humidity at which the powder is stored does not influence the quality of the top spread layer after a total of $\mathbf{4 0}$ layers as long as the relative humidity around the spread powder bed is much lower. It is therefore assumed that the desorption of the adsorbed water on the powder surface happens relatively fast. Yet, when combining both investigation methods-spreading just one single layer and spreading 40 layers - it can be concluded that there must be a critical humidity level at which the quantity of adsorbed water is so high that the spreading of layers cannot be sufficiently successful. Further, if this high level of humidity were to be present in the chamber during the entire printing process, then humidity would certainly have a clearly negative influence on the whole process, as shown in the investigation of the formation of empty spots. Yet, although this statement clearly applies at least to the examined L718 AMPO powder, it cannot be claimed that it applies to other powders as well.

Furthermore, there are two additional aspects that have to be considered. The first one is that it takes about $30 \mathrm{~min}$ to fill the powder into the machine before a real build job is started. During this time, the balance between adsorbed water and relative humidity in air is already established and the former is thus changed, provided that the powder is stored at a different humidity level than that prevailing in the room where the $3 \mathrm{D}$ printer is located. The second one is that the process chamber is flooded and purged with dry inert gas to establish the required low oxygen level inside, which takes an additional 30 to $45 \mathrm{~min}$. Due to this constant dry gas flow inside the machine, the water will desorb on its own, maybe even before manufacturing starts. Thus, such a conditioned powder would only be processed about an hour later and would have enough time and opportunities to desorb the adsorbed water, thus more or less approaching the same state as powders stored in dry conditions.

\section{Summary}

In this study it was found that adsorbed water and therefore high humidity levels can have a detrimental influence on the additive manufacturing process if this humidity was present during the entire build job. Furthermore, it was also observed that the adsorbed water quickly desorbs and an equilibrium with the environment is established quite rapidly. Due to this and several other aspects concerning the timing, humidity should not be a problem at least when considering the L718 AMPO superalloy powder investigated here (for powders in which humidity during storage causes irreversible changes, this might be different). It was also shown that there has to be a critical humidity level at which it is no longer possible to spread dense powder layers, since the dry conditioned powder did produce dense ones and the humid conditioned one did not.

Once more the Hall funnel flow test was shown not to be a suitable method for testing powders used for L-PBF technologies, since the powder did not flow freely through the funnel but still could be spread and processed without any problems.

Funding. Open access funding provided by TU Wien (TUW).

Open Access This article is licensed under a Creative Commons Attribu tion 4.0 International License, which permits use, sharing, adaptation, distribution and reproduction in any medium or format, as long as you give appropriate credit to the original author(s) and the source, provide a link to the Creative Commons licence, and indicate if changes were made. The images or other third party material in this article are included in the article's Creative Commons licence, unless indicated otherwise in a credit line to the material. If material is not included in the article's Creative Commons licence and your intended use is not permitted by statutory regulation or exceeds the permitted use, you will need to obtain permission directly from the copyright holder. To view a copy of this licence, visit http://creativecommons.org/licenses/by/4.0/.

\section{References}

1. Raj, B. A.; Jappes, J. T. W.; Khan, M.A.; et al.: Direct Metal Laser Sintered (DMLS) process to develop Inconel 718 alloy for turbine engine components, Optik, 202 (2020), 163735

2. Pollock, T. M.; Tin, S.: Nickel-Based Superalloys for Advanced Turbine Engines: Chemistry, Microstructure and Properties, Journal of Propulsion and Power, 22 (2006), pp 361-374 
3. Patterson, R.; Cox, A.; Reuth, E. V.: Rapid Solidification Rate Processing and Application to Turbine Engine Materials, JOM, 32 (1980), pp 34-39

4. Prescott, J. K.; Barnum, R. A.: On powder flowability, Pharmaceutical Technology, 24 (2000), pp 60-84

5. Vock, S.; Klöden, B.; Kirchner, A.; et al.: Powders for powder bed fusion: a review, Progress in Additive Manufacturing, 4 (2019), pp 383-397

6. Lumay, G.; Boschini, F.; Traina, K.; et al.: Measuring the flowing properties of powders and grains, Powder Technology, 224 (2012), pp 19-27

7. Hare, C.; Zafar, U.; Ghadiri, M.; et al.: Analysis of the dynamics of the FT4 powder rheometer, Powder Technology, 285 (2015), pp 123-127

8. Microtrac Retsch $\mathrm{GmbH}$ : Ensuring High Quality in the Additive Manufacturing Process, https://www.microtrac.de/dltmp/www/ 5e396c14-fe94-4af0-83c0-7f30c3c9c754-49caf39811f8/tr_additive_ manufacturing_vs_0519_en.pdf (01.07.2020)

9. Anton Paar GmbH: Methods for Powder and Granular Media Characterization with the Anton Paar Powder Cell, https://www.antonpaar.com/corp-en/services-sup-port/documentfinder/applicationre ports/methods-for-powder-and-granular-media-characterizationwith-the-anton-paar-powder-cell/ (17.05.2019)

10. Szemkus, S.; Jahn, S.; Matthes, S.; et al.: Avoiding Humidity Influences for Robust Powder Bed Fusion Processing, Proceedings of EuroPM2017 Congress \& Exhibition, Milan, IT, European Powder Metallurgy Association (EPMA), Shrewsbury, UK, 2017, Paper number 3684646

11. Cordova, L.; Campos, M.; Tinga, T.: Assessment of moisture content and its influence on laser beam melting feedstock, Proceedings of Euro PM2017 Congress \& Exhibition, Milan, IT, European Powder Metallurgy Association (EPMA), Shrewsbury, UK, 2017, Paper number 3684585

12. Olsson, E.; Sundin, S.; Karlsson, L.; et al.: Evaluation of Flowability Measurement Methods and Investigation of Influencing Factors for Flowability of Metal Powders for Additive Manufacturing, Proceedings of Euro PM2019 Congress \& Exhibition, Maastricht, NL, European Powder Metallurgy Association (EPMA), Shrewsbury, UK, 2019, Paper number 4346392

13. Lefebvre, L.-P.; Bernier, F; Orsoni-Wiemer, N.; et al.: Rheology of Powders: Assessing the Robustness and Impact of Humidity, Tri- bocharging, Particle Size and Composition, Proceedings of: Euro PM2019 Congress \& Exhibition, Maastricht, NL, European Powder Metallurgy Association (EPMA), Shrewsbury, UK, 2019, Paper number 4342266

14. LPW Technology: Moisture Analysis of Metal Powder Samples by Karl Fischer Titration; Brochure, Runcorn, United Kingdom, 2017

15. Mellin, P.; Zavalis, T.; Tingö, L.; et al.: Moisture content analysis of metal powders using oven desorption followed by Karl Fischer titration, Metal Powder Report, 75 (2019), pp 34-39

16. Nan, W.; Pasha, M.; Bonakdar, T.; et al.: Jamming during particle spreading in additive manufacturing, Powder Technology, 338 (2018), pp 253-262

17. Mitterlehner, M.; Danninger, H.; Gierl-Mayer, C.; et al.: Study on The Influence of the Blade on Powder Layers Built in Powder Bed Fusion Processes for Additive Manufacturing, BHM Berg- und Hüttenmännische Monatshefte, 165 (2020), pp 157-163

18. Chang, H. C.; Wang, L.-C.: A Simple Proof of Thue's Theorem on Circle Packing, 2010, arXiv:1009.4322

19. Mitterlehner, M.; Danninger, H.; Gierl-Mayer, C.: A New Method For Describing The Morphology Of Powder Layers In Direct Laser Melting, Proceedings of 3rd Metal Additive Manufacturing Conference 2018, Vienna, AT, Austrian Society for Metallurgy and Materials (ASMET), Leoben, AT, 2018, pp 31-40

20. Mitterlehner, M.; Danninger, H.; Gierl-Mayer, C.: Study On Segregation Effects in Powder Layers Built In Powder Bed Fusion Processes For Additive Manufacturing, Proceedings of Euro PM2019 Congress \& Exhibition, Maastricht NL, European Powder Metallurgy Association (EPMA), Shrewsbury, UK, 2019, Paper number 4346412

21. Mitterlehner, M.; Danninger, H.; Gierl-Mayer, C.: Study on the layer building of powders in powder bed fusion processes for Additive Manufacturing, Proceedings of Euro PM2018 Congress \& Exhibition, Bilbao ES, European Powder Metallurgy Association (EPMA), Shrewsbury UK, 2018, Paper number 3988826

22. Mitterlehner, M.; Danninger, H.; Gierl-Mayer, C.; et al.: Processability of Moist Superalloy Powder by SLM, BHM Berg- und Hüttenmännische Monatshefte, this issue

Publisher's Note. Springer Nature remains neutral with regard to jurisdictional claims in published maps and institutional affiliations. 